\title{
RESPONSE OF THE PERIAPICAL TISSUE OF DOGS' TEETH TO THE ACTION OF CITRIC ACID AND EDTA
}

\author{
Cristina Berthold SPERANDIO ${ }^{1}$, Luiz Fernando Machado SILVEIRA ${ }^{2}$, Lenita Aver de ARAÚJO ${ }^{2}$, \\ Josué MARTOS ${ }^{3}$, Ashwin MALSHE ${ }^{4}$
}

\author{
1- DDS, MSC, Department of Clinics, Dental School, Federal University of Pelotas, Pelotas, RS, Brazil. \\ 2- DDS, MSc, PHD, Professor, Department of Clinics, Dental School, Federal University of Pelotas, Pelotas, RS, Brazil. \\ 3- DDS, PHD, Professor, Department of Clinics, Dental School, Federal University of Pelotas, Pelotas, RS, Brazil. \\ 4- BS, Electronics Engineering, University of Mumbai, India; PhD Student, State University of New York, New York, NY, USA.
}

Corresponding address: Prof. Dr. Luiz Fernando Machado Silveira, Faculdade de Odontologia de Pelotas, Universidade Federal de Pelotas Rua Gonçalves Chaves 457 - Pelotas, RS, Brazil - 96015-560 - Phone/Fax: 55-53-2224439 - e-mail: lufersil.sul@ terra.com.br

Received: June 11, 2007 - Modification: September 11, 2007 - Accepted: October 24, 2007

\begin{abstract}
Th

he purpose of this study was to analyze the inflammatory response of dog's periapical tissues to $17 \%$ trisodium EDTA salt ( $\mathrm{pH}$ 8.0) and $1 \%$ citric acid ( $\mathrm{pH}$ 2.0). Saline was used as a control. Six adult dogs were used as the biological model of the study. The experimental units comprised 56 roots of mandibular molars (first and second) and premolars (first, second and third). After coronal opening, pulpectomy and root canal instrumentation were performed using the above-mentioned irrigating solutions. After 24 and 48 hours, the animals were euthanized and the teeth and their supporting tissues were removed and histologically processed. The sections were stained with hematoxylin and eosin and analyzed histopathologically with a light microscope at x100 magnification. The histological analysis focused on the occurrence of acute inflammatory response. The presence of swelling, vasodilatation and inflammatory cells were evaluated and the degree of inflammation was determined for each case. Data were analyzed by Fisher's exact test using the SPSS software with a confidence interval of 95\% (p<0.05). 17\% EDTA and $1 \%$ citric acid caused inflammatory responses in dog's periapical tissues with no significant differences to each other or to saline (control) at either the 24-hour $(\mathrm{p}=0.482)$ or 48 -hour $(\mathrm{p}=0.377)$ periods. It may be concluded that the inflammatory response was of mild intensity for the tested substances.
\end{abstract}

Uniterms: Citric acid. Ethylenediaminetetraacetic acid. Biocompatibility.

\section{INTRODUCTION}

The cleaning and disinfection role of the irrigating solutions in the complex protocol of the endodontic therapy is essential for treatment success. As McComb and Smith ${ }^{10}$ (1975) demonstrated the presence of a dentin layer attached to the root canal walls, the irrigating solutions should act on both organic and inorganic compounds.

Among the irrigants used for removal of inorganic compounds are the chelating agents and inorganic acids represented by ethylenediaminetetraacetic acid (EDTA) and citric acid, respectively ${ }^{7,10,11,13}$. Some authors have focused their studies on the biological effects of citric acid solutions $^{1,8}$.

The biocompatibility of citric acid and EDTA in the pulp and periapical tissues induces an inflammatory response of variable intensity and depth depending on the methodology used. Cotton and Siegel ${ }^{5}$ (1978) and Baumgartner, et al. ${ }^{3}$ observed no severe or irreversible damage on the human dental pulp. Sterrett, et al. ${ }^{12}$ (1993) and Malheiros, et al. ${ }^{8}$ (2005) stated that the effects observed on the human dentin may vary according to the concentration and application time.

McInnes-Ledoux, et al. ${ }^{9}$ (1985) reported that, in monkeys, $1 \%$ citric acid showed severe effects on the pulpal tissues. Leonardo, et al. ${ }^{6}$ (1984) observed a good tolerance of the periapical tissues to EDTA on dog's teeth, while Zina, et al. ${ }^{15}$ (1981) using trisodium EDTA in dog's teeth did not observe any damage on the healing process of the pulp stump and periapical tissues.

Chan, et al. ${ }^{4}$ (1999) observed that in human pulp cell cultures, the toxicity of $0.5 \%$ and $1 \%$ citric acid is proportional to the concentration and exposure time, whereas other studies observed in rats that citric acid was less irritating than EDTA and ethyleneglycol-bis(2-aminoethoxy)tetraacetic acid (EGTA) ${ }^{14}$. Amaral, et al. ${ }^{1}$ (2007) observed that both EDTA and citric acid showed cytotoxic effects on macrophages, though citric acid produced less cytotoxic. Malheiros, et al. ${ }^{8}$ (2005) demonstrated in cultured fibroblasts and in rats (rattus novergicus) in vivo, respectively, that, if applied at high concentrations, citric acid leads to a delay in cell growth and has an irritating effect in vivo. 
Based on the endodontic biologic principles, the purpose of this study was to evaluate, histopathologically, the periapical tissue response of dog's teeth submitted to root canal therapy with two demineralizing chemical substances: $1 \%$ citric acid and $17 \%$ trisodium EDTA salt.

\section{MATERIALAND METHODS}

Three different solutions were used in this study: $17 \%$ trisodium EDTA salt (, pH 8.0; Chemical Lab. UCPel, Pelotas, RS, Brazil), $1 \%$ citric acid ( $\mathrm{pH} 2.0$; Curativa Pharmacy, Pelotas, RS, Brazil) and saline (Texon Co., RS, Brazil) as the control.

Six adult dogs from the central laboratory of UFPel were selected as the biological model of the study. The experimental sample comprised 56 roots of mandibular molars (first and second; $\mathrm{n}=13$ ) and premolars (first, second and third; $n=22$ ). Seven out of the 35 teeth were lost during the histological processing. Twenty-eight teeth with two roots remained, thus totaling 56 roots. Each root was considered as sample unit.

The animals were sedated with an intravenous injection of 2\% Virbaxyl (Virbac Co., SP, Brazil) and then anesthetized with Thiopental (Cristália Chemical Products, SP, Brazil). After oral asepsis with $0.12 \%$ chlorhexidine, coronal opening was performed under rubber dam isolation. Access to the pulp chamber was gained with \#1012, 1015 and 1016 diamond burs (KG Sorensen, São Paulo, SP, Brazil) and the convenience shape was given with an Endo Z bur (DentsplyMaillefer, Ballaigues, Switzerland). Pulpectomy was performed with a Hedströen file and the working length was determined $1 \mathrm{~mm}$ short of the radiographic apex with K-files (Dentsply-Maillefer).

Root canals were instrumented with four K-files (Dentsply-Maillefer) of greater sizes than that of file used for root canal length determination. During biomechanical preparation, the number of irrigations and volume of the irrigating solution were standardized in $16 \mathrm{~mL}$ for premolars and $32 \mathrm{~mL}$ for molars with the aid of disposable syringes and 30x3, 30x4 and 30x5 hypodermic needles (BectonDickinson, São Paulo, SP, Brazil). In all phases of biomechanical preparation, either one of the test or the control substances were used as auxiliary irrigant.

When instrumentation was completed, the root canal was filled with the test solution for 5 minutes to allow an intimate contact. After drying, the canal entrance was sealed with disinfected gutta-percha followed by composite Prisma APH (Dentsply Ind. e Com. Ltda, Petrópolis, RJ, Brazil) below the occlusion line.

After 24 and 48 hours of the treatment, the animals were euthanized and the teeth removed and fixated in $10 \%$ formalin solution. Thereafter, the teeth were decalcified by immersion in 1:1 formic acid and sodium citrate solution followed by $5 \%$ nitrate acid. The specimens were embedded in fused paraffin Histosec (Merck KGaA, Darmstadt, Germany), cut with a microtome at the apical foramen in serial $6-\mu \mathrm{m}$-thick sections, which were stained with hematoxylin and eosin and mounted on glass slides. The sections that best represented the area of pulp-periodontium communication were selected and examined with a light microscopy at x 100 magnification.

The histologic analysis considered the occurrence of an acute inflammatory response, so the presence of swelling, vasodilatation and inflammatory cells was evaluated and the degree of inflammation was determined for each case.

For systematic examination of the specimens, a squared and numbered (with 100 indexed crosses (+) of equal dimension) eyepiece grid (NE21 mm; Graticules Ltd, Kent, UK), was introduced into one of the eyepieces of the microscope. Of the total of 100 crosses that composed the net, approximately 50 would cover the periodontal space, being the remainder occupied by the root, dental canal and alveolar bone, which were excluded from the analysis. Three fields of the periodontal ligament were evaluated: its most central area in relation to the apical foramen and two lateral margins. For each evaluated field, we considered the number of points coinciding with the occurrence of the three primary events of inflammatory reaction: swelling, vasodilatation and presence of inflammatory cells. From all analyzed fields, the most representative area of inflammatory degree was selected. The following criteria were used: mild inflammation - when each parameter was coincident with a maximum of 4 crosses; moderate inflammation - when at least 2 parameters were coincident with at least 5 and at most 9 crosses; severe inflammation - when at least 2 parameters were coincident with 10 or more crosses.

Chi-square test could have been used to assess differences in the efficacy of the three substances. However, as the expected frequencies for a few cells were less than 5, chi-square test was not deemed appropriate. Alternatively, Fisher's exact test was used to overcome the problem due to small cell frequencies because it requires a non-zero frequency in each cell. Hence, the category "severe" was eliminated because there was no observation for that level. The resulting contingency table was used for Fisher's exact test is reproduced as Table 2 and 4 . The data were analyzed with a confidence interval of $95 \%(\mathrm{p}<0.05)$ using the SPSS software (SPSS 14.0, SPSS Inc., Chicago, IL, USA).

\section{RESULTS}

The two tailed $p$ value generated by Fisher's exact test for the above contingency table was 0.482 (for the 24-hour exposure time) and 0.377 (for the 48 -hour exposure time). As both $\mathrm{p}$ values were greater than 0.05 , the null hypothesis of independence was accepted, which means that the three substances did not have different efficacy at the either of the study intervals.

The results of the histologic analysis of the inflammatory response observed in dogs' teeth after contact with EDTA, citric acid and saline, after 24 and 48 hours, are presented in the Tables 1 and 2.

In order to provide the necessary adjustment for the statistical analysis, the scores 1, 2 and 3 were attributed to the mild (Figure 2), moderate (Figure 3 ) and severe (Figure 
4) inflammation degrees, respectively, which differ from the normal aspect (Figure 1). There was no significant difference in the inflammation degree among the tested substances within the 24 hour $(\mathrm{p}=0.482)$ or 48 hour $(\mathrm{p}=0.377)$ periods.

TABLE 1- Tested substances according to the inflammatory response after 24 hours

\begin{tabular}{|c|c|c|c|c|}
\hline Substance & Number of repetitions & Inflammatory response & Score & Incidence \\
\hline \multirow[t]{3}{*}{ EDTA } & 11 & Mild & 1 & 9 \\
\hline & & Moderate & 2 & 2 \\
\hline & & Severe & 3 & - \\
\hline \multirow[t]{3}{*}{ Citric acid } & 8 & Mild & 1 & 7 \\
\hline & & Moderate & 2 & 1 \\
\hline & & Severe & 3 & - \\
\hline \multirow[t]{3}{*}{ Saline } & 10 & Mild & 1 & 6 \\
\hline & & Moderate & 2 & 4 \\
\hline & & Severe & 3 & - \\
\hline
\end{tabular}

TABLE 2- Tested substances according to the inflammation response after 48 hours

\begin{tabular}{|c|c|c|c|c|}
\hline Substance & Number of repetitions & Inflammatory response & Score & Incidence \\
\hline \multirow[t]{3}{*}{ EDTA } & 9 & Mild & 1 & 6 \\
\hline & & Moderate & 2 & 2 \\
\hline & & Severe & 3 & 1 \\
\hline \multirow[t]{3}{*}{ Citric acid } & 11 & Mild & 1 & 4 \\
\hline & & Moderate & 2 & 6 \\
\hline & & Severe & 3 & 1 \\
\hline \multirow[t]{3}{*}{ Saline } & 7 & Mild & 1 & 5 \\
\hline & & Moderate & 2 & 2 \\
\hline & & Severe & 3 & 1 \\
\hline
\end{tabular}

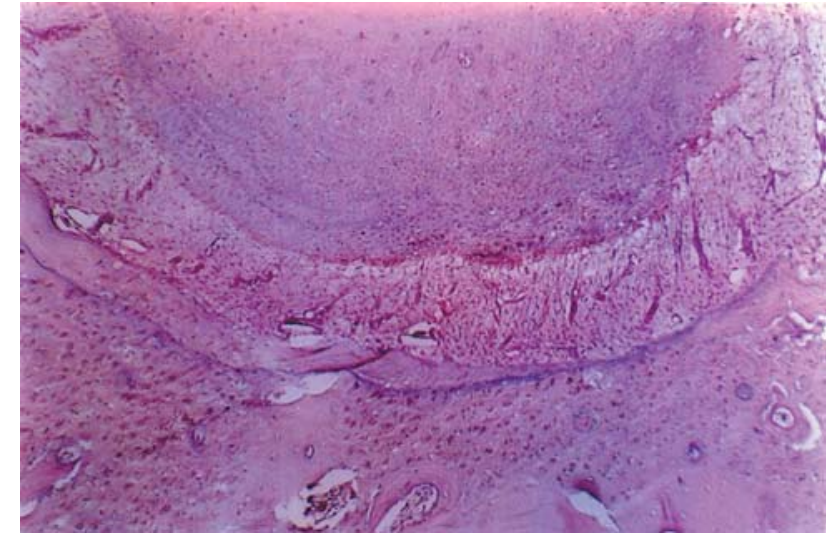

FIGURE 1- Normal aspect of the periodontium (H.E., original magnification: $\mathrm{x} 100$ )

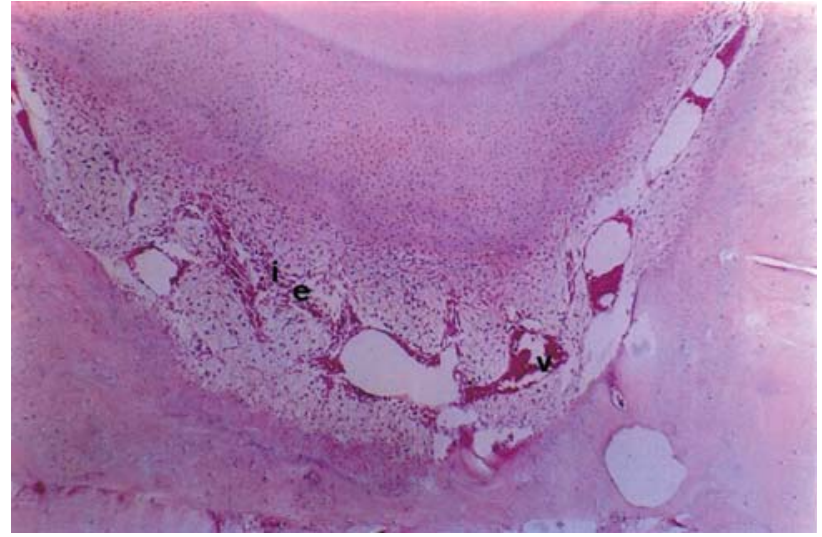

FIGURE 2- Mild inflammation. vasodilatation (v); inflammatory cells (i); swelling (e) (H.E., original magnification: $\mathrm{x} 100)$ 


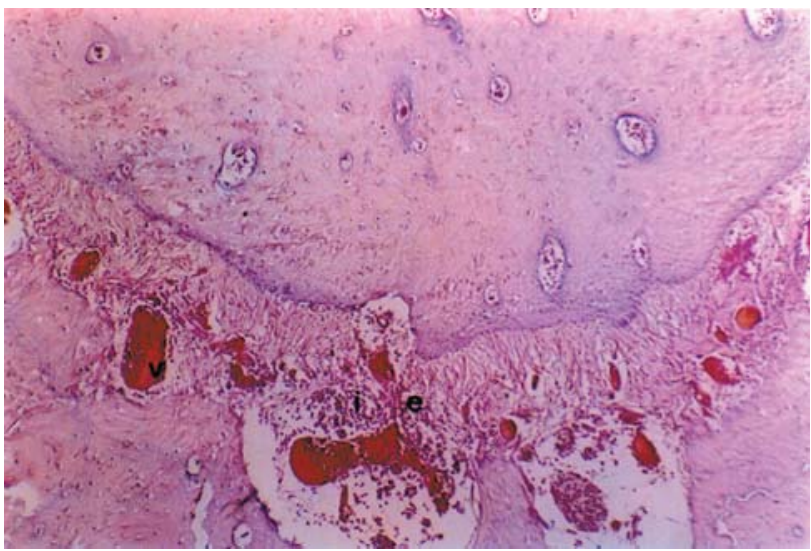

FIGURE 3- Moderate inflammation. vasodilatation (v); inflammatory cells (i); swelling (e) (H.E., original magnification: $x 100)$

\section{DISCUSSION}

In the present study, the sample comprised the roots instead of molar and premolar teeth because, after pulpectomy, the surgical wounds behave independently even if submitted to the same treatment. The 24- and 48hour periods were established because, though presenting a relative antimicrobial activity, the tested substances, are not indicated for this use and after longer observation periods there would be the risk of bacterial contamination, especially in the control group.

The method proposed for inflammation degree evaluation consisted of using a net of eyepiece reticular scale adapted to the ocular of the microscope, which allowed the quantification of the events composing the inflammatory process, i.e., swelling, vasodilatation and presence of inflammatory cells in the apical region. Therefore, the classification of the inflammatory response in mild, moderate and severe was determined by the counting.

The results obtained with EDTA in relation to the control group demonstrated a good tolerance by the periapical tissues. Similar findings have been reported by Zina, et al. ${ }^{15}$ (1981) and Leonardo, et al. ${ }^{6}(1984)$, the latter evaluating the tissue response in dogs' teeth. The statistical analysis showed that even though there was a severe degree inflammation within 48 hours, there was no significant difference between both periods.

Citric acid showed a similar behavior as that of EDTA and saline at both periods and, though not statistically significant, it showed a higher degree of inflammation at 48 hours compared to the shorter period. This result differs from those of previous studies that used citric acid for cavity cleaning $^{5,9}$ and evaluated the response to pulp tissues instead of to periapical tissues.

The findings of the present study and of other authors ${ }^{1,8}$ disagree from those reported by Chan, et al. ${ }^{4}$ (1999) who observed an increase in the inflammation degree with a longer exposure time in cell cultures. Citric acid is an organic acid that takes part in the Krebs cycle in the human cells, being therefore biologically acceptable.

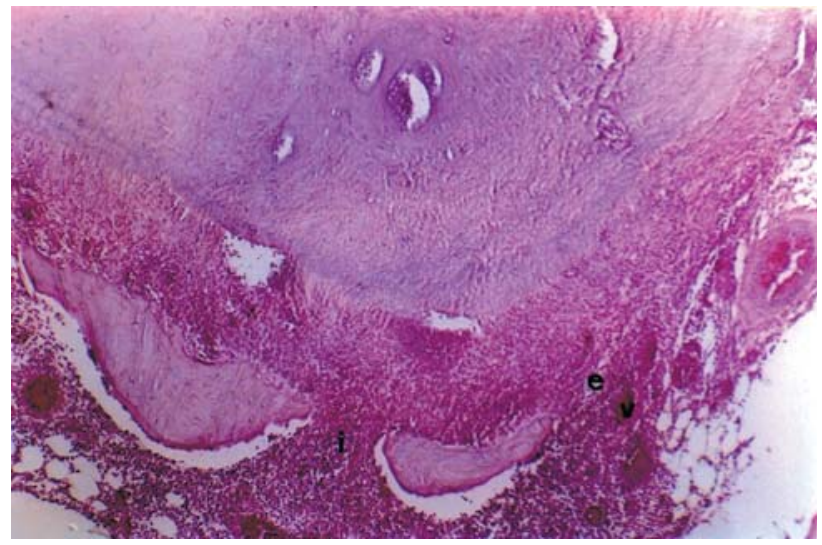

FIGURE 4- Severe inflammation. vasodilatation (v); inflammatory cells (i); swelling (e) (H.E., original magnification: $\mathrm{x} 100$ )

The results of the control group showed that an inflammatory response is a natural consequence of pulpectomy. Comparison of the substances in both studied periods ( 24 and 48 hours) did not show statistically significant differences. This fact indicates that, although these two substances have a low superficial tension, even in multiple foramen conditions, other factors referring to their physicochemical properties and the site of application, control their diffusion. Regarding EDTA, its activity is limited by the presence of organic material ${ }^{2}$, in addition to promoting the coagulation of proteins, which form of a mechanical barrier that avoids its diffusion towards the periapical tissues.

Citric acid has the property of not promoting collagen selling, which occurs with most acids. This justifies its use for histological preparations in the form of sodium citrate, in demineralization processes. This aspect could allow a higher diffusion of this substance, but its acidic characteristics provide cauterizing properties, due to its low $\mathrm{pH}$.

Both EDTA and citric acid compared to the control group showed a potential for a mild inflammation, with no statistically significant difference to each other. The clinical use of either EDTA or citric acid should be done with caution to prevent their extrusion to the periapical tissues. Citric acid showed similar conditions for clinical use as those of EDTA, as it has similar characteristics regarding the property as an inorganic solvent, removal of smear layer, improvements in $\mathrm{NaOCl}$ properties when associated to it and a satisfactory tissue tolerance. Under the tested conditions, the outcomes justify the clinical use of citric acid but in a cautious manner.

\section{CONCLUSIONS}

Under the experimental conditions of this study, the obtained results showed that $17 \%$ EDTA and $1 \%$ citric acid caused inflammatory responses in dog's periapical tissues with no significant differences from saline within the evaluated time periods ( 24 and 48 hours). $17 \%$ EDTA and 
$1 \%$ citric acid produced similar inflammatory reaction to each other at both the shorter and the longer time period. It may be concluded that the inflammatory response to the tested substances was of mild intensity.

\section{REFERENCES}

1- Amaral KF, Rogero MM, Fock RA, Borelli P, Gavini G. Citotoxicity analysis of EDTA and citric acid applied on murine resident macrophages culture. Int Endod J. 2007;40:338-43.

2- Apostolopoulos AX, Buonocore MG. Comparative dissolution rates of enamel, dentin and bone. I: Effect of the organic matter. J Dent Res. 1996;45:1093-100.

3- Baumgartner JC, Brown CM, Mader CL. Scanning electron microscopic evaluation of root canal debridement using saline, sodium hypochlorite and citric acid. J Endod. 1984;10:525-31.

4- Chan C, Jeng J. Morphological alterations associated with the citotoxic and citostatic effects of citric acid on cultured human dental pulp cells. J Endod. 1999;25:354-8.

5- Cotton WR, Siegel RL. Human pulpal response to citric acid cavity cleanser. J Am Dent Assoc. 1978;96:639-44.

6- Leonardo MR, Comelli RC, Esberard RM. Immediate root canal filling: the use of cytophylactic substances and noncytotoxic solutions. J Endod. 1984;10:1-8.

7- Loel DA. Use of acid cleanser in endodontic therapy. J Am Dent Assoc. 1975;90:148-51.

8- Malheiros CF, Marques MM, Gavini G. In vitro evaluation of the cytotoxic effects of acid solutions used as canal irrigants. J Endod. 2005;31:746-8

9- McInnes-Ledoux P, Cleaton-Jonis PE, Austin JC. The pulpal response to dilute citric acid smear removers. J Oral Rehabil. $1985 ; 12: 215-28$.

10-McComb D., Smith DC. A preliminary scanning electron microscopic study of root canals after endodontic procedures. J Endod. $1975 ; 1: 238-42$

11 - Machado-Silveiro LF, González-Lopez S, González-Rodríguez MP Decalcification of root canal dentine by citric acid, EDTA and sodium citrate. Int Endod J. 2004;37:365-9.

12- Sterrett JD, Bankey T, Murphy HJ. Dentin demineralization. The effect of citric acid concentration and application time. J Clin Periodontol. 1993;20:366-70.

13- Stewart GG. A scanning electron microscopic study of the cleanser effectiveness of three irrigating modalities on the tubular structure of dentin. J Endod. 1998;24:485-6.

14- Sousa SMG, Bramante CM, Taga EM. Biocompatibility of EDTA, EGTA and citric acid. Braz Dent J. 2005;16:3-8.

15- Zina O, Souza V, Holland R. Influence of chelant agents on dentin permeability and on the healing process of periapical tissues after root canal treatment. Rev Odontol UNESP. 1981;10:27-32. 